\title{
Evaluation and treatment of spinal metastases: an overview
}

\author{
W. Bradley Jacobs, M.D., and Richard G. Perrin, M.D., M.S.C., F.R.C.S(C), F.A.C.S. \\ Division of Neurosurgery, Department of Surgery, University of Toronto, Ontario, Canada
}

\begin{abstract}
Metastases to the spine are a common and somber manifestation of systemic neoplasia. The incidence of spinal metastases continues to increase, likely a result of increasing survival times for patients with cancer. Historically, surgery for spinal metastases has consisted of simple decompressive laminectomy. Results obtained in retrospective case series, however, have shown that this treatment provides little benefit to the patient. With the advent of better patient-related selection practices, in conjunction with new surgical techniques and improved postoperative care, the ability of surgical therapy to play an important and beneficial role in the multidisciplinary care of cancer patients with spinal disease has improved significantly. Controversy remains, however, with respect to the relative merits of surgery, radiotherapy, chemotherapy, or a combination of these treatments.

In this topic review, the literature on spinal column and spinal cord metastases is collated to provide a description of the presentation, investigations, indications for surgical therapy, and the role of adjuvant cancer therapies for patients with spinal metastases. In addition, the authors discuss the different surgical strategies available in the armamentarium of the neurosurgeon treating patients with spinal metastasis.
\end{abstract}

KEY WORDS • metastasis • spine • neurooncology

Cancer therapies continue to evolve and improve. As a result, in patients with many types of systemic neoplasms survival time continues to increase. ${ }^{5}$ Related to this increased prevalence of longer-term cancer survivors, there is likely to be an increase in the incidence of metastatic disease of the spinal column and the spinal cord. As metastases to the spine are common, neurosurgeons must be well versed in the many nuances of treatment. Indeed, the principles of clinical and surgical management of spinal metastases can serve as a paradigm for suitable and successful management of all spinal tumors.

Although surgery is now established as a viable, beneficial treatment option in the treatment of spinal metastases, ${ }^{100}$ controversy exists regarding the relative merits of surgery, radiotherapy, chemotherapy, and a combination of these therapies in different patient groups. ${ }^{10,20,47,52,53}$

\section{INCIDENCE OF SPINAL METASTASES}

The vertebral column is the most common site of skeletal metastases. ${ }^{38}$ Spinal metastases are a very frequent manifestation of systemic neoplasia, with up to $70 \%$ of

Abbreviations used in this paper: $\mathrm{CT}=$ computerized tomography; IDEM = intradural extramedullary; $\mathrm{MR}=$ magnetic resonance; $\mathrm{VB}=$ vertebral body . cancer patients harboring secondary spinal disease. ${ }^{24,30}$ Metastases are the most common group of spinal column tumors, with approximately 18,000 new cases diagnosed in North America each year. ${ }^{29}$ Up to $10 \%$ of cancer patients will develop symptomatic secondary spinal lesions, ${ }^{30,93}$ with multiple levels of involvement present in 40 to $70 \%$ of symptomatic cancer patients ${ }^{39,49}$ (Fig. 1). Cancers from breast, lung, prostate, hemopoietic (for example, lymphoma or multiple myeloma), and renal origins account for the vast majority of extradural spinal metastases. ${ }^{1,34,65,67,88,89}$ This reflects both the prevalence of these particular neoplasms, as well as their predilection for metastasis to bone. In addition, the spinal lesion represents the first manifestation of cancer in 12 to $20 \%$ of patients who present with symptoms related to spinal metastases. ${ }^{83,85}$

Classic autopsy investigations have demonstrated that the distribution of extradural metastases is related to the size of the vertebrae. ${ }^{101}$ Thus, metastatic lesions are most commonly located in the lumbar region, less so in the thoracic spine, and least often $(<20 \%)$ in the cervical spine. ${ }^{1,65}$ Despite this distribution, symptomatic lesions occur more frequently in the thoracic region (70\%) than in the lumbosacral or cervical segments. ${ }^{27}$ Particular predilection for thoracic levels about $\mathrm{T}-4^{55}$ and the thoracolumbar junction has been noted. ${ }^{65}$ The smaller size of the thoracic spinal canal in relation to the thoracic spinal cord accounts for this discrepancy. ${ }^{30}$ 


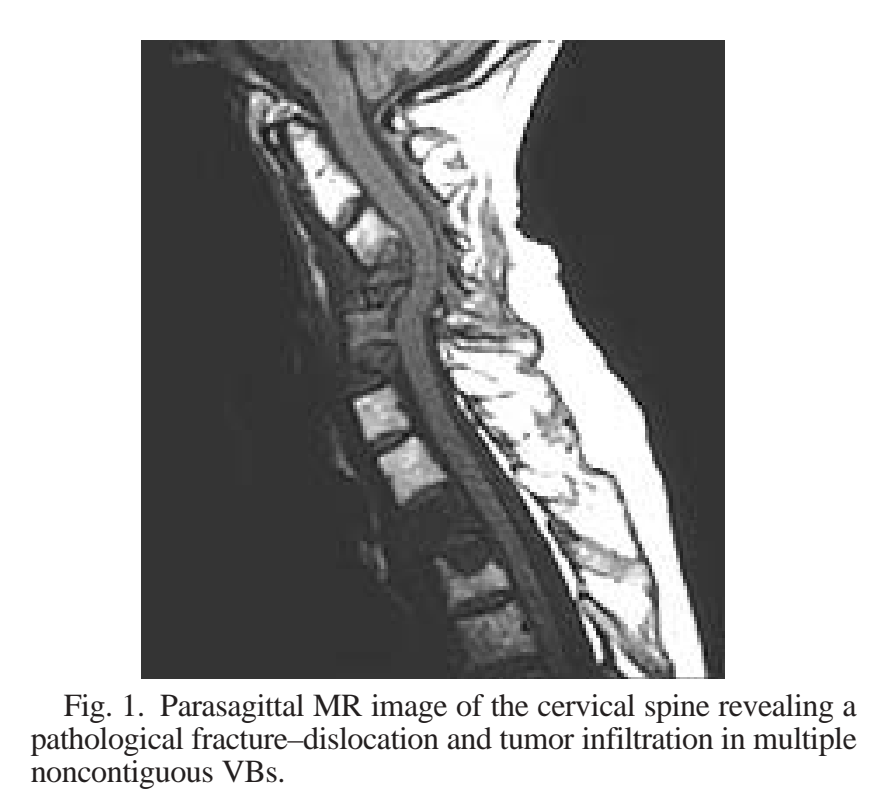

\section{CLASSIFICATION OF METASTASES}

Spinal metastases, like all spinal tumors, are classified according to their anatomical distribution. Upwards of $95 \%$ of spinal metastases are extradural lesions. ${ }^{22,71,83} \mathrm{In}-$ tradural extramedullary tumors comprise the majority of the remaining lesions, whereas intramedullary metastases are rare, comprising approximately $0.5 \%$ of spinal axis metastases. ${ }^{71,83}$

Most extradural metastases are initially osseous lesions that originate within a portion of the vertebra and subsequently impinge on the thecal sac secondary to rapid, destructive growth. Lesions located purely posteriorly (Fig. 2) or anteriorly to the thecal sac are uncommon; the majority have a predilection for lateral displacment (that is, antero- or posterolateral) with respect to the spinal cord. Despite the frequency with which neoplastic extradural compression occurs, the dura mater is a strong anatomical barrier to neoplastic invasion and is rarely breached. Lesions located purely within the epidural compartment and without bone involvement account for only a small fraction of extradural metastases, with hemopoietic malignancies noted to have a predilection for such anatomic localization. ${ }^{50}$

Intradural extramedullary spinal metastases most commonly occur as tertiary drop metastases from intracranial intradural secondary lesions ${ }^{83}$ and are often entangled within the nerve roots of the cauda equina (Fig. 3). Melanoma, lymphoma, and medulloblastoma are common primaries. In a series reported by Chow, et al., ${ }^{12}$ in which the authors examined only IDEM metastases of nonneurogenic origin, $80 \%$ of patients also harbored intracranial metastatic foci, also suggesting drop metastases as the most common mechanism of spread. In this same series, the most frequent histological subtype was adenocarcinoma, and the most frequent primary source was the lung. Intramedullary spinal cord metastatic disease accounts for only $8.5 \%$ of all metastases to the central nervous system and $2.1 \%$ of all cancers ${ }^{18}$ in case series published before the advent of MR imaging. More sophis-

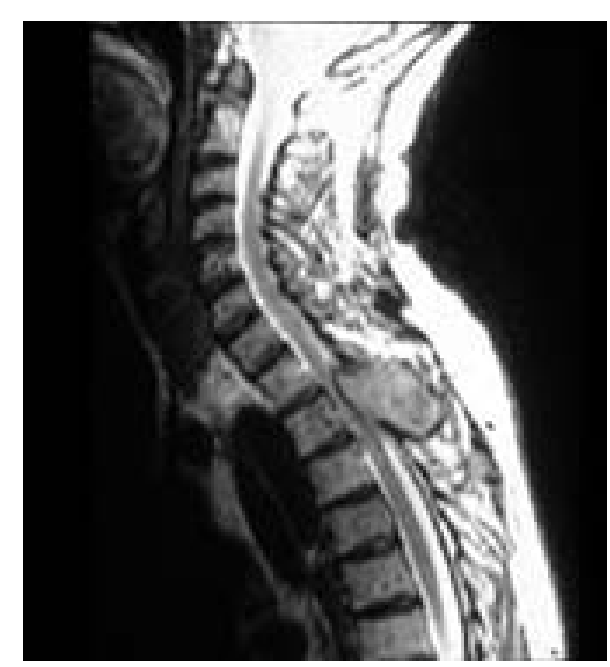

Fig. 2. Parasagittal MR image of the cervicothoracic spine revealing a spinal metastasis arising from the posterior elements of T-2.

ticated neuroimaging is likely to increase the prevalence of this difficult-to-diagnose entity. ${ }^{15}$ The majority of intramedullary metastases arise from the lung, with small cell carcinoma being the predominant histological subtype. Breast, colorectal, renal, melanoma, thyroid, and lymphoma have all been reported..$^{15,18,84}$ Like IDEM metastases, intramedullary lesions are found most often in patients with concomitant brain metastases.

\section{PATHOPHYSIOLOGICAL MECHANISMS OF SPINAL METASTASES}

The majority of systemic neoplasms are thought to metastasize to the extradural spinal axis by hematogenic

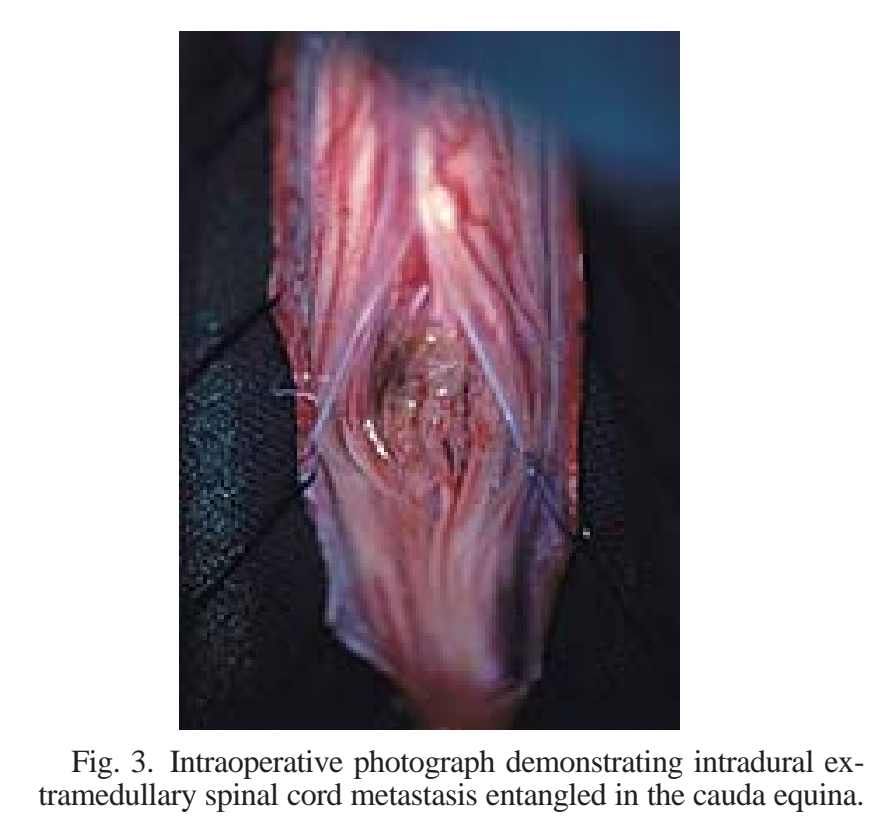

Neurosurg. Focus / Volume 11 / December, 2001 
spread. This is believed to occur by means of one of two mechanisms: 1) via arterial emboli to the abundant bone marrow of the VBs and subsequently into the anterior or posterior extradural space through venous channels, ${ }^{3}$ or 2 ) via retrograde spread through the valveless extradural Batson's venous plexus. ${ }^{6}$ Batson originally conceived the theory of retrograde venous seeding to account for the high incidence of prostatic metastases to the spinal column. More recently this mechanism has been used to account for the spread of many other systemic neoplasms. ${ }^{35,66}$ A third mechanism of extradural metastasis is direct invasion/extension of tumor into the epidural space, most characteristic of hemopoietic neoplasms such as lymphoma. ${ }^{32}$

The pathophysiological mechanism of IDEM metastases is thought to involve cerebrospinal fluid spread from intracranial secondary lesions, or arterial hematogenic routes. ${ }^{12,83}$ In a similar manner, intramedullary metastases are believed to result from leptomeningeal carcinomatosis with subsequent cerebrospinal fluid spread, or as a result of hematogenic emboli from a primary or secondary pulmonary lesion. ${ }^{15,18,84}$

\section{CLINICAL DIAGNOSIS}

A characteristic clinical syndrome is produced by spinal column metastasis. ${ }^{27,55,57,69,71}$ Pain is the initial symptom in 90 to $95 \%$ of patients. This pain is usually local and associated with tenderness elicited by palpation over the spinous process at the level of involvement. On occasion a component of radicular pain, radiating in the distribution of the nerve root at the involved level, may accompany neck or back pain. Pain of a severe, burning, dysesthetic nature is often associated with IDEM metastatic lesions, ${ }^{71}$ whereas pain that is aggravated by movement and alleviated by immobility should raise suspicion of spinal instability and pathological fracture-dislocation. ${ }^{70}$ In general, myofascial, discogenic, and spondylotic pain are more common in the cervical and lumbar spine and are relieved with rest. Spinal metastasis-induced pain most commonly localizes to the thoracic segments and is often worse with rest and at night. ${ }^{27}$ Local back or neck pain can be present for a significant duration before a correct diagnosis is reached; the median time to diagnosis in one study was 2 months. ${ }^{27}$ Unfortunately, the correct diagnosis is often not made until signs and symptoms of spinal cord compromise are manifest. It is axiomatic that back or neck pain in a cancer patient is secondary to spinal metastasis until proven otherwise.

Neurological compromise in the form of weakness, sensory loss, and sphincter disturbance usually occurs after the onset of pain. At the time of diagnosis, sensory or motor deficits are present in 38 to $76 \%$ of patients, and $50 \%$ of patients are nonambulatory (secondary to pain and/or neurological deficit). ${ }^{27,67}$ Sphincter disturbance is also common, with $37 \%$ of patients requiring placement of a urinary catheter in one series. ${ }^{40}$ Brown-Séquard syndrome, or a variation thereof, is a common neurological finding at the time of diagnosis in patients with intramedullary spinal metastasis. ${ }^{84}$ The natural history of spinal metastasis is relentless progression to complete and irreversible paraplegia unless timely treatment is undertaken. ${ }^{7}$

\section{Differential Diagnosis}

Symptomatic secondary spinal lesions are a common manifestation of systemic neoplasia, and the presence of back or neck pain in a cancer patient should never be minimized. In some cancer patients presenting with axial pain and/or signs and symptoms of spinal cord dysfunction, however, another cause may account for their clinical syndrome (Table 1). A careful, thorough clinical history and physical examination coupled with appropriate laboratory and diagnostic imaging investigations, as outlined in the following sections, readily delineate metastatic spinal tumors from other more benign differential diagnostic entities.

\section{DIAGNOSTIC INVESTIGATIONS}

Laboratory investigations and diagnostic neuroimaging studies are indispensable in the evaluation of the known cancer patient with signs and symptoms suggestive of spinal cord metastasis, as well as in the patient who presents without history of systemic neoplasia.

\section{General Investigations}

A useful, logical first step is to perform routine blood studies consisting of a complete blood count, albumin, electrolyte panel, liver enzyme assays, blood urea nitrogen, and serum creatinine. Information about the immunological and nutritional status of the patient can be obtained, as can knowledge of renal dysfunction secondary to malignancy determined by increased creatinine or blood urea nitrogen levels. Alterations in liver function may suggest the presence of liver metastasis or, more rarely, a primary liver carcinoma. Hypercalcemia is a common finding in patients with metastatic bone disease and requires prompt treatment to avoid cardiac electrical dysfunction. Serum electrophoresis and urine for Bence Jones protein levels are useful tests in the diagnosis of suspected multiple myeloma. Assays for prostate-specific antigen aid in the determination of prostate carcinoma, which is a common primary source of spinal metastasis. Chest radiography and abdominal ultrasonography are useful screening tools for primary neoplasms, whereas CT scanning of the chest, abdomen, and pelvis provides detailed information about the presence of neoplasm and should be readily performed when metastatic disease is suspected.

TABLE 1

Differential diagnosis in spinal cord compression in patients with systemic cancer

\begin{tabular}{|c|}
\hline Differential Diagnosis \\
\hline $\begin{array}{l}\text { degenerative spinal disorders (disc herniation, spinal stenosis, spon- } \\
\text { dylolisthesis) }\end{array}$ \\
\hline meningeal carcinomatosis/lymphomatosis \\
\hline infectious diseases (osteomyelitis, discitis, epidural abscess) \\
\hline radiation-induced myelopathy \\
\hline epidural hematoma (secondary to coagulopathy) \\
\hline transverse myelitis \\
\hline paraneoplastic syndromes \\
\hline $\begin{array}{l}\text { vascular malformations (arteriovenous malformation, dural arterio- } \\
\text { venous fistula, cavernoma) }\end{array}$ \\
\hline
\end{tabular}




\section{Diagnostic Neuroimaging of the Spinal Axis}

Modern neurodiagnostic imaging studies are indispensable in the evaluation and treatment of patients with metastatic spinal tumors. These studies are used to diagnose, stage, and plan treatment in patients with metastatic lesions, as well as to follow them postoperatively.

Spinal Radiography. Plain radiographs of the spine remain a valuable and readily available initial imaging study. Anteroposterior and lateral radiographs demonstrate abnormal findings in up to $90 \%$ of patients with symptomatic spinal metastasis. ${ }^{77,91}$ Lytic lesions and vertebral collapse are common $;{ }^{74}$ however, both osteoblastic and -sclerotic alterations also occur, especially with breast and prostatic metastasis. Plain X-ray film findings include pedicle erosion (that is, the "winking owl" sign), paraspinal soft-tissue shadows, wedge compression, and pathological fracture-dislocation (Fig. 4). Intervertebral disc margins are invariably spared in metastatic tumor inva-

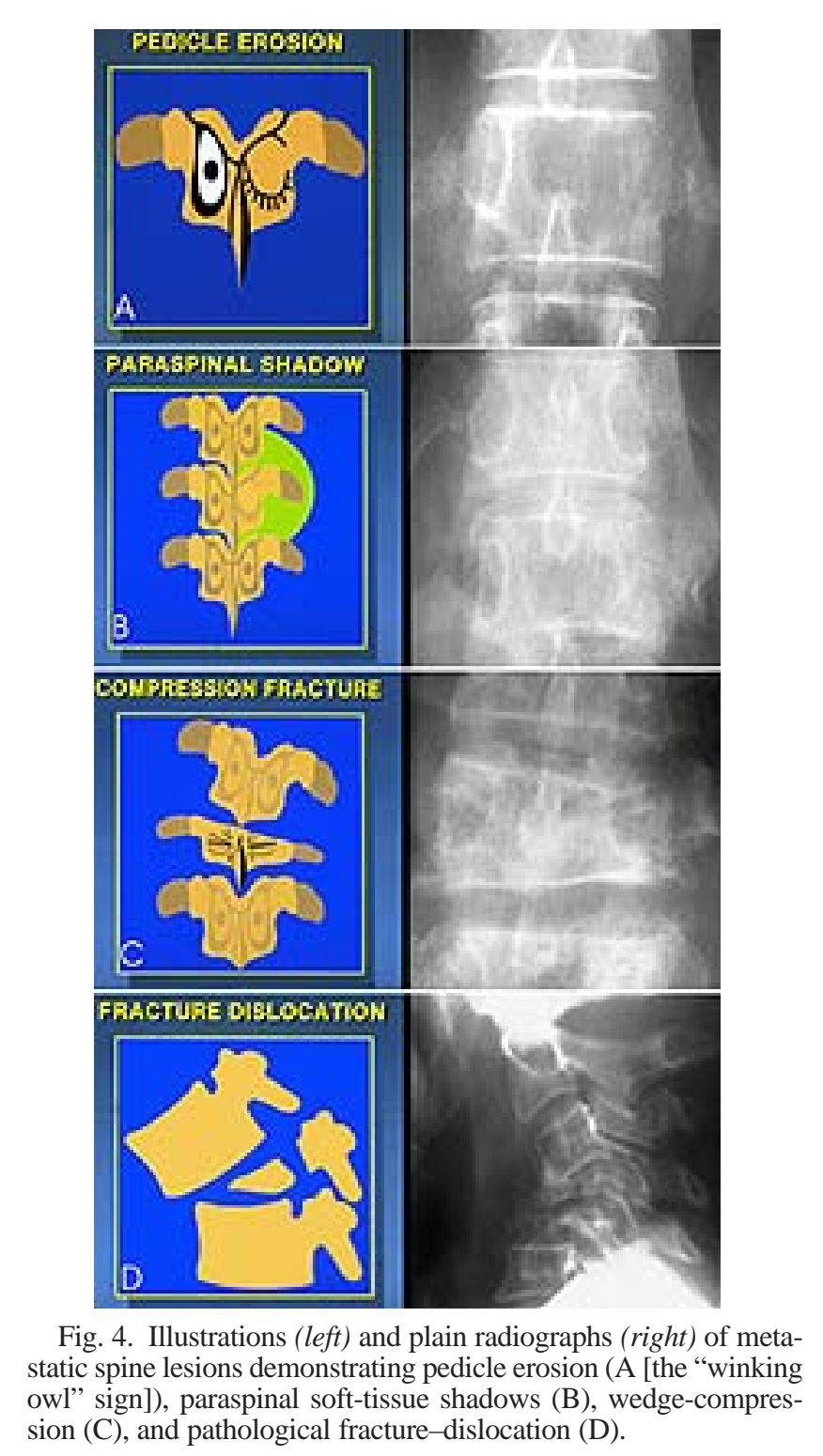

sion, contrasting with the disc erosion commonly observed with infectious entities.

Local bone destruction of $50 \%$ is required before a lesion can be detected on plain x-ray films. ${ }^{9}$ In a high proportion of patients with symptomatic secondary spinal lesions abnormalities are demonstrated on plain radiographs, but in up to $26 \%$ of the cases early metastatic lesions can be missed. ${ }^{104}$ Consequently, clinicians investigating patients with a high suspicion of metastatic spinal neoplasms should arrange expeditious CT and/or MR imaging investigations, even if normal findings are observed on plain radiographs.

Myelography. Traditionally, myelography (Fig. 5) had been the gold standard for determining the level of spinal cord compression. This status has been largely supplanted by MR imaging studies. Myelography continues to play a valuable role, however, especially in cases in which MR imaging is not readily available, is contraindicated secondary to ferromagnetic implants, or in patients unable to tolerate MR imaging. Anatomical localization and the relation of the lesion to the dura, spinal cord, and nerve roots are readily facilitated by myelography. It is desirable to visualize the entire length of the spinal axis to rule out cord compression at multiple levels. Thus, if contrast material does not readily flow rostrally past a region of spinal block after a lumbar injection, then a cisternal injection may also be required. Myelography performed via lumbar puncture in the presence of a complete spinal block carries the risk of spinal cord herniation and subsequent neurological deterioration, with deterioration reported in $14 \%$ of patients in one study. ${ }^{44}$ Cisternal myelography has not been associated with this risk.

Computerized Tomography Scanning. The principal use of CT scanning is in the assessment of the osseous ar-

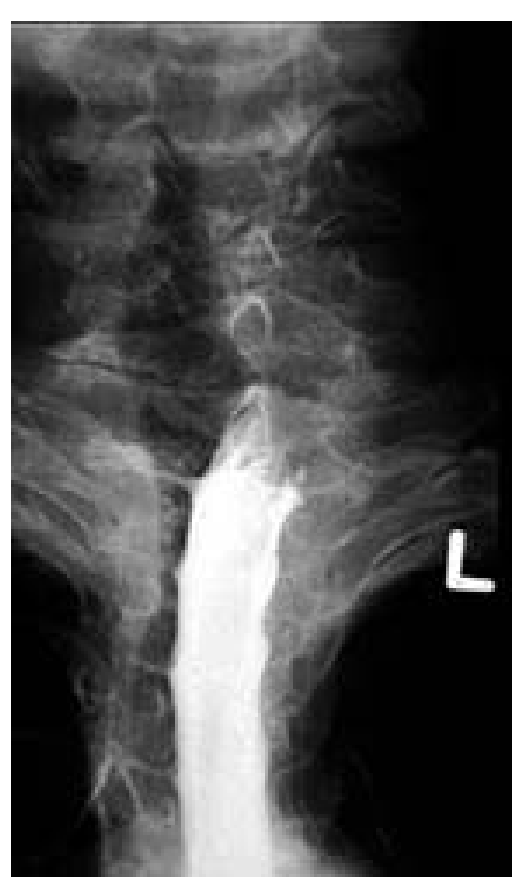

Fig. 5. Lumbar myelogram revealing a complete block at the cervicothoracic junction secondary to an extradural metastasis. 
chitecture of the spinal axis because MR imaging does not provide optimum images of bone. Computerized tomography scanning provides important information regarding the degree of tumor association with cortical bone and the extent of neoplastic destruction (Fig. 6). Thus, CT scanning is an important complement to MR imaging. In patients in whom MR imaging cannot be performed, CT scanning is particularly useful when conducted immediately following myelography. Computerized tomography myelography provides better anatomical detail of the spinal axis than either CT or myelography alone. The information acquired from CT myelography is often comparable with that obtained using MR imaging. ${ }^{42}$

Magnetic Resonance Imaging. Magnetic resonance imaging provides unparalleled visualization of the spinal column and spinal cord and is the neuroimaging method of choice in patients with suspected spinal tumors. It has been demonstrated to facilitate the earlier diagnosis of spinal metastases ${ }^{4}$ than other modalities. It is superior in depicting epidural and bone marrow tumor infiltration, and it delineates the extraosseous soft-tissue component of a neoplasm from the normal paraspinal soft tissue and neural structures. ${ }^{48}$ In addition to its diagnostic utility, MR imaging information is essential to the process of thorough surgical planning. Gadolinium enhancement further increases the sensitivity of MR imaging investigations, because metastases invariably enhance. Visualization of the entire vertebral axis in multiple orthogonal planes is easily accomplished, a goal that is important given the high incidence of multiple vertebral levels of tumor infiltration. ${ }^{39,49}$ Studies show that the results of MR imaging investigations alter therapeutic decisions in a significant number of patients, especially with regard to the addition or modification of radiotherapy. ${ }^{14}$

Bone Scanning. Given the current sensitivity of MR imaging in detecting metastases in the vertebral axis, the radioisotope bone scan is most useful as a sensitive screening or follow-up test to assess the total burden of osseous disease. Data obtained using this modality are invaluable in the process of optimum patient selection.

\section{MANAGEMENT}

The treatment of patients with symptomatic secondary spinal lesions is undertaken to relieve pain and to preserve

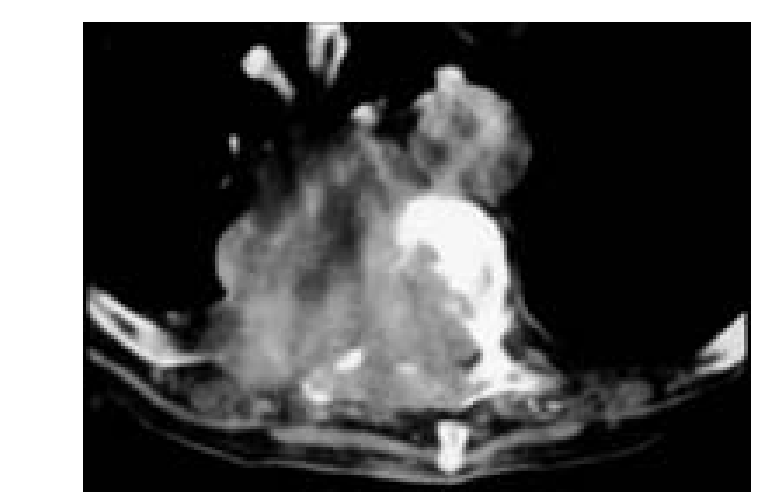

Fig. 6. Axial CT scan obtained through the midthoracic spine revealing extensive tumor-induced cortical bone destruction. or restore neurological function. Cure is not a realistic expectation in patients with metastatic spinal tumors. Palliation is the reasonable goal; life expectancy is often relatively short, with median survival ranging from 4 to 15 months in various series. ${ }^{82,89,100,102}$ These modest goals contribute immeasurably to the quality of life in cancer patients and decrease the burden of care.

\section{Corticosteroid Medication Administration}

Administration of an intravenous or oral corticosteroid agent serves as a vital adjuvant therapy in the treatment of patients with spinal metastases causing spinal cord compression. ${ }^{21}$ Improvement in neurological status is often documented after steroid administration. The mechanism of action of corticosteroids in this setting is not completely understood, but reduction in peritumoral vasogenic spinal cord edema has been documented experimentally and is at least partially responsible..$^{97,98}$ The optimum dose of corticosteroid agent to be administered also remains open to debate; in one study the investigators recommended high-dose dexamethasone (100-mg bolus followed by $4 \mathrm{mg}$ every 6 hours) because it provided better protection than more standard dosing (10 $\mathrm{mg}$ followed by $4 \mathrm{mg}$ every 6 hours). ${ }^{31}$ No added advantage has been found with higher dosages. ${ }^{99}$ It is standard practice to administer $10 \mathrm{mg}$ of dexamethasone intravenously once a diagnosis is established, followed by $4 \mathrm{mg}$ every 6 hours, until definitive treatment is commenced. A tapering regimen is then instituted. Medical complications such as exacerbation of diabetes mellitus, hypertension, immunocompromise, gastric ulceration, acute delirium, and wound infection must be carefully monitored. Although it has been common practice to administer steroids prior to commencing spinal irradiation, the authors of a recent study have demonstrated that in patients without myelopathy dexamethasone need not be administered. ${ }^{59}$

\section{Radiation Therapy}

Radiotherapy plays an important role in the treatment of metastatic spinal tumors. Many consider it to be the mainstay of therapeutic intervention..$^{8,46,47,60}$ Spinal irradiation is particularly effective in the treatment of various radiosensitive histological subtypes of metastases, such as hemopoietic tumors and prostate carcinoma. Excellent response to radiotherapy in the setting of spinal cord compression is found in $30 \%$ of all patients, including those with more radioresistant lesions such as breast carcinoma and metastatic melanoma. ${ }^{54}$

The response to radiotherapy must be considered in relation to the parameters of pain relief and functional status. Response to radiotherapy alone has been reported to be 66 to $80 \%,{ }^{47,60}$ including improvement in motor dysfunction in one half of patients and stabilization of symptomatology in one third. ${ }^{60}$ Pretreatment functional status is the most important prognostic indicator. Significant correlation between ambulatory status before radiotherapy and the median length of survival after treatment initiation has been noted. ${ }^{41,53,60}$

The standard radiation dose schedule for metastatic spinal tumors consists of 20 to $30 \mathrm{~Gy}$ administered in five to 10 treatment sessions to the area of spinal cord compression; many variations exist and are related to the general 
medical status of the patient and the extent of spinal tumor. Short-course radiotherapy ( 8 Gy given in two sessions) has also been shown to be as advantageous as more protracted schemes and to cause less severe side effects. ${ }^{61}$ Some have also advocated intraoperative radiotherapy, but this procedure is not widely conducted. ${ }^{87}$ In those patients presenting with complete paraplegia of several days' duration, relief of pain should be the treatment goal; this can be accomplished by administering a single 8-Gy fraction.

Side effects are generally mild. Radiation-induced esophagitis may occur transiently 1 to 2 weeks following treatment of upper thoracic lesions. Irradiation of the lower thoracic and upper lumbar spine often produces nausea and vomiting, resulting as the radiation beam exits through the epigastrium. This side effect is most pronounced after the first two to three fractions and is generally controlled by providing standard antiemetics. Radiation-induced myelopathy is an important late-onset complication but is rare with standard dosimetry. ${ }^{104}$

\section{Surgical Therapy}

The role of the neurosurgeon in the treatment of patients with metastatic spinal tumors continues to evolve. Historically, decompressive laminectomy was performed in an attempt to alleviate cord compression. Large retrospective reviews, however, have demonstrated that this surgical approach is beneficial in only a minority $(<40 \%)$ of patients. ${ }^{16,90}$ Furthermore, in studies investigating the effi- cacy of radiotherapy alone or in combination with simple laminectomy, the authors found no difference in outcome. ${ }^{8,105}$ Such poor laminectomy-related results are not surprising, given the lateral (antero- or posterolateral) displacement of most spinal metastases in relation to the dural sac; purely posterior lesions are uncommon. Simple laminectomy thus provides inadequate decompression of the spinal cord and nerve roots in the majority of patients. Laminectomy alone is also likely to exacerbate mechanical spinal instability, especially in the case of vertebral collapse, a common finding in patients with extradural metastatic lesions. The failure to individualize surgical approach based on tumor location has likely contributed to the failure of traditional surgical methods (laminectomy) in the treatment of spinal metastases. ${ }^{33}$

Refinement of surgical approaches such as the posterolateral (Fig. 7A) and anterior exposures (Fig. 7B) for spinal cord decompression, as well as the ongoing development and evolution of spinal stabilization apparatus and techniques, has greatly improved the efficacy of surgical intervention. ${ }^{17,36,93}$ As a first-line therapy surgery remains a desirable option-numerous studies suggest that wound dehiscence and infections are drastically increased when surgery is performed after primary radiotherapy. ${ }^{26,63} \mathrm{Ra}-$ diotherapy also appears to be less effective when epidural spinal cord compression is associated with a paravertebral soft-tissue mass. In this situation, improvement in functional status has been shown when resection is used as a first-line therapy and followed by radiotherapy. ${ }^{51}$

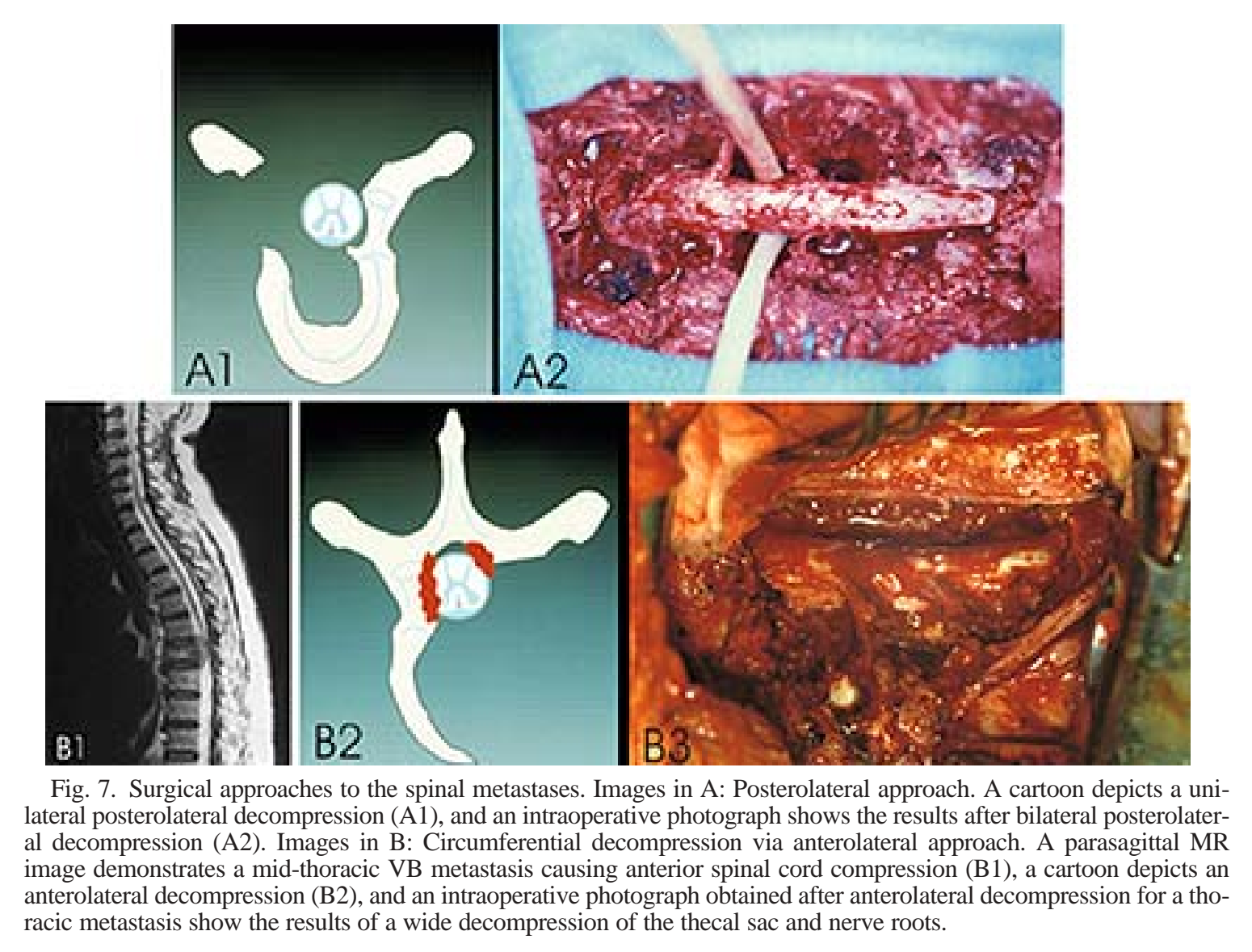


Indications and Contraindications to Surgery. Optimum surgery-related outcome requires careful patient selection (Table 2). Emergency surgery is mandated in the setting of rapidly progressive or advanced paraplegia, because complete and irreversible spinal cord injury will occur if prompt decompression of the thecal sac and nerve roots is not performed. Patients harboring a pathological fracture-dislocation have an unstable spine and also require surgery for decompression and stabilization of the spinal axis. De novo radiotherapy can exacerbate this instability and cause further cord compression. In cases in which the diagnosis of spinal metastases is not certain (that is, in a cancer patient with symptoms believed to be the result of a cause other than symptomatic secondary spinal lesions, or in a patient without a history of cancer), surgery should be performed. In these cases surgery serves a diagnostic as well as therapeutic purpose. Finally, in patients in whom radiotherapy has failed to control the progression of symptoms or in those with a known radioresistant tumor, surgery should be considered the treatment of choice.

Surgical decompression cannot reverse a complete paralysis of greater than 24 hours' duration and should not be performed. Short-course radiotherapy that provides pain relief is a more prudent course of action. Radiotherapy provides excellent local control of radiosensitive lesions such as lymphoma or multiple myeloma. Patients with a known highly radiosensitive lesion are thus best served by undergoing primary spinal irradiation. Adhering to the tenet that successful palliation is the primary goal in management of spinal metastases, those patients with a heavy burden of disease, a limited life expectancy and/or extreme medical comorbidities are not well served by surgical therapy. Spinal irradiation should be considered the first-line therapy in such cases.

Preoperative Embolization. Metastases originating from thyroid and renal cell carcinoma are particularly vascular. Excision can be associated with catastrophic intraoperative blood loss. ${ }^{96}$ Endovascular embolization is a well-established procedure ${ }^{80}$ that often greatly decreases the vascularity of spinal metastases (Fig. 8), decreasing intraoperative blood loss and facilitating more complete lesion resection and spinal decompression. ${ }^{43,58}$ Thus, the need for embolization should be carefully considered before beginning resection.

TABLE 2

Indications and contraindications to surgery for spinal metastases

\section{Indications \& Contraindications}

surgical indications

rapidly progressing or far-advanced paraplegia histological diagnosis in an unknown primary spinal instability \& pathological fracture-dislocation failure of radiotherapy/known radioresistant lesion relative contraindications to surgery

longstanding complete paralysis $(<24 \mathrm{hrs})$

highly radiosensitive tumor (lymphoma, myeloma)

multiple levels of involvement

poor life expectancy $(<3 \mathrm{mos})$

extreme medical comorbidity

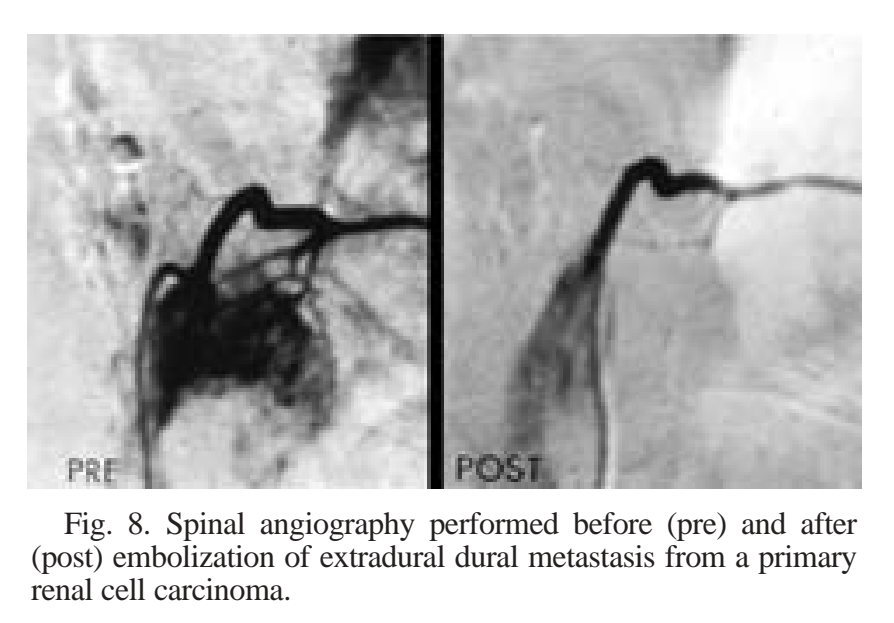

\section{Surgical Strategies}

Any successful surgical strategy must ensure both decompression of the dural sac and nerve roots as well as stabilization of the spinal column (Fig. 9). Spinal instability may be present as a result of tumor-induced bone destruction or the surgical decompression. It is important to individualize the surgical approach to the spine on a patient-by-patient basis. The surgical approach to spinal metastases may be ventral (anterior or anterolateral) or dorsal (posterior or posterolateral). An adequate posterior approach involves posterolateral (uni- or bilateral) decompression, allowing circumferential decompression of the thecal sac and nerve roots. Anterior-approach decompression involves corpectomy. In either case (invariably, following corpectomy) spinal instability will be precipitated. Consequently, the implantation of spinal instrumentation is always necessary (Fig. 10). If a longer-term survival is anticipated, use of a bone autograft is appropriate. Otherwise, an artificial structural support can be fashioned from methylmethacrylate and used in conjunction with the implanted mechanical construct. The plethora of devices and techniques available for spinal reconstruction after metastasis resection attests to the fact that no single method is supreme (Tables 3 and 4).

In the past decade there has been renewed interest and

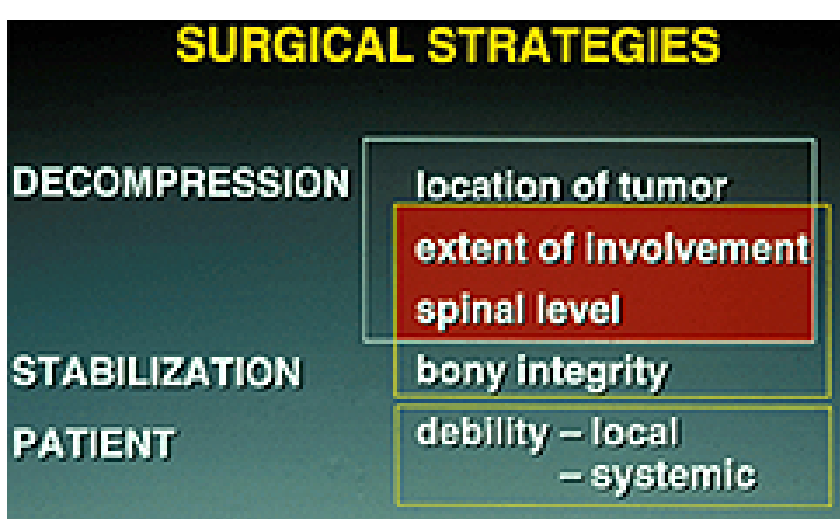

Fig. 9. Schematic diagram outlining the factors to be considered in planning surgery for spinal metastases. 


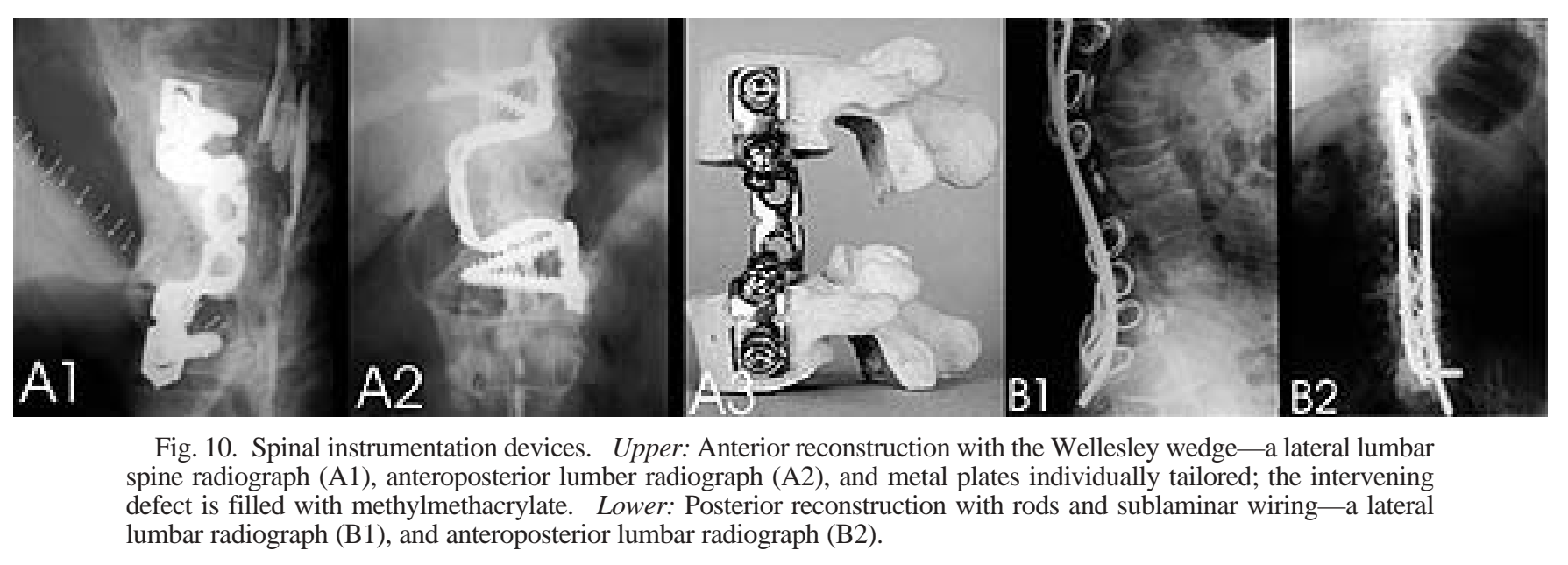

rapid evolution in the surgical management of spinal metastases. The introduction of new surgical techniques and reconstructive instruments has brought with it a move to more extensive and radical surgical procedures. . $^{217,25,28,}$ 93,95 These modern surgical methods have been conceived with the goal of affording maximum therapeutic benefit to the patient. Their exact utility, however, remains to be proven.

The decision to perform anterior or posterior procedures depends on numerous interrelated factors. ${ }^{72}$ Each approach has a specific role, and no single procedure is universally more advantageous than another.

Tumor Location. Whereas laterally situated lesions are most common, extradural metastases can present in all manners of spatial relation to the thecal sac. Generally, lesions involving the VB and causing anterior or anterolateral compression are best approached via anterior or anterolateral routes in which vertebral corpectomy is performed a biomechanically sound stabilization construct is placed. Laterally situated lesions can often be adequately resected via a posterolateral approach. Only a minority of cases in which isolated posterior compression is present are best served by laminectomy. Intradural extramedullary and intramedullary lesions are almost always approached via a wide posterior laminectomy.

Spinal Level. Extreme rostrally and caudally located lesions pose a specific challenge. Although extensive and

TABLE 3

Selected anterior spinal fixation methods*

\begin{tabular}{ll}
\hline \hline \multicolumn{1}{c}{ Original Proponents \& Yr } & \multicolumn{1}{c}{ Method } \\
\hline Cloward, 1958 & Cloward \\
Robinson \& Southwick, 1960 & Smith-Robinson \\
Cross, et al., 1971 & MMA \\
Ono \& Tada, 1975 & metal prosthesis \\
Fielding, et al., 1979 & corpectomy/iliac crest \\
Sundaresan, et al., 1984 & MMA/double K-wire \\
Perrin \& McBroom, 1988 & Wellesley wedge \\
Matsui, et al, 1994 & ceramic prosthesis \\
Gokaslan, et al., 1998 & MMA/locking plate \\
Schulte, et al., 2000 & bioglass/polyurethane prosthesis \\
\hline
\end{tabular}

$*$ MMA = methylmethacrylate. high morbid-related procedures are available that allow access to the craniocervical junction, most patients with metastatic lesions are not suitable candidates for these interventions, because such surgical therapies are contrary to the basic philosophy of successful palliation and preservation of quality of life. Additionally, anterior stabilization and instrumentation is very difficult at both the craniocervical and lumbosacral junctions. As such, in most cases, the best initial intervention is posterior decompression and stabilization in cases in which these extreme levels are affected.

Extent of Involvement. Extradural metastases involving one or two contiguous VB levels is best approached via anterior or anterolateral routes, because these allow for direct decompression and the possibility of a construction of a sound fusion mass. ${ }^{72}$ If three or more contiguous levels require attention, however, decompression is best achieved using a posterolateral approach combined with posterior fusion and placement of instrumentation, or a combined anterior-posterior procedure.

Cortical Bone Integrity. Multiple levels of tumor infiltration are commonly found. ${ }^{39}$ Thus, it is important to determine the integrity of the VBs adjacent to the region in which the decompression is performed. If adjacent bone is compromised, anterior fusion after anterolateral decompression may not be possible. In such cases, the surgeon should consider posterolateral decompression and placement of posterior instrumentation as a safer alternative.

TABLE 4

Selected posterior spinal fixation methods

\begin{tabular}{ll}
\hline \hline Original Proponent \& Yr & \multicolumn{1}{c}{ Method } \\
\hline Rogers, 1942 & interspinous wiring \\
Robinson \& Smith, 1955 & posterolat facet fusion \\
Harrington \& Dickson, 1976 & Harrington rods \\
Roy-Camille, et al., 1976 & Roy-Camille plates \\
Livingston \& Perrin, 1978 & rib struts \\
Perrin \& Livingston, 1982 & MMA/sublaminar wires \\
Holness, 1984 & Halifax clamp \\
Luque, 1986 & Luque rectangle \\
Steffee, et al., 1986 & variable spine plating \\
Mirovsky, et al., 1999 & Hartshill rectangle \\
\hline
\end{tabular}


Patient Debility. Local or systemic debility is often a factor when contemplating surgery in the patient with spinal metastases. Anterior cervical approaches through a radiation-exposed neck can be fraught with difficulty and complication. Patients with primary or secondary pulmonary lesions are often unable to tolerate the operative stresses associated with transthoracic or retroperitoneal exposures. Many cancer patients have systemic comorbidities that make consideration of the less debilitating of two possible spinal procedures the more reasonable option. To subject individuals with limited life expectancy to lengthy procedures and subsequent long convalescence periods is to betray the primary goal of treatment-successful palliation.

\section{OUTCOME}

The prognosis of the patients treated for symptomatic secondary spinal lesions is variable, given the pretreatment heterogeneity of the patient population. By the same token, results obtained in published studies defy comparison and the drawing of universal conclusions. In general, the authors of recent surgery-based series report 80 to $90 \%$ relief of pain, as well as up to $90 \%$ stabilized or improved neurological status. ${ }^{11,29,79,89,100,102}$ The outcome after treatment of symptomatic secondary spinal lesions depends on a number of variables (Table 5), the most durable of which is the pretreatment neurological status; intervention has little chance of restoring useful motor function in individuals in whom complete paralysis has developed prior to treatment.

\section{SUMMARY}

Metastatic spinal neoplasms are the most commonly encountered tumors of the spine. All neurosurgeons will be involved with the evaluation and treatment of these patients. Successful treatment requires recognition of the characteristic clinical presentation of this entity, combined with appropriate investigations and treatment planning. The management of patients with spinal metastases has evolved greatly over the last decade. Radiotherapy can no longer be considered the universal first-choice treatment, because the advent of new surgical strategies has greatly increased the benefit of surgical interventions. In this drive to expand our surgery-related armamentarium, rapid technical advances have been made. Patients with spinal metastases now frequently undergo radical procedures in an attempt to achieve maximum local disease control. Neurosurgeons, however, must not lose sight of the primary goal of treatment for these patients: successful palliation

\section{TABLE 5}

Prognostic factors for surgery for spinal metastases

Prognostic Factor

extent of pretreatment deficit

duration of symptoms

histology of metastatic tumor

location of tumor

extent of primary tumor control and improvement in quality of life. Application of this principle in a setting of multidisciplinary cooperation among neurosurgeons, orthopedic surgeons, and radiation oncologists will provide the maximum benefit for this large group of cancer patients.

\section{References}

1. Abdu WA, Provencher M: Primary bone and metastatic tumors of the cervical spine. Spine 23:2767-2777, 1998

2. Abe E, Kobayashi T, Murai $\mathrm{H}$, et al: Total spondylectomy for primary malignant, aggressive benign, and solitary metastatic bone tumors of the thoracolumbar spine. J Spinal Disord 14: 237-246, 2001

3. Arguello F, Baggs LB, Duerst RE, et al: Pathogenesis of vertebral metastasis and epidural spinal cord compression. Cancer 65:98-106, 1990

4. Avrahami E, Tadmor R, Dally O, et al: Early MR demonstration of spinal metastases in patients with normal radiographs and CT and radionuclide bone scans. J Comput Assist Tomogr 13:598-602, 1989

5. Bailar JC III, Gornik HL: Cancer undefeated. N Engl J Med 336:1569-1574, 1997

6. Batson OV: The function of the vertebral veins and their role in the spread of metastases. Ann Surg 112:138-149, 1940

7. Botterell EH, Fitzgerald GW: Spinal cord compression produced by extradural malignant tumours. Can Med Assoc J 80: 791-796, 1959

8. Byrne TN: Spinal cord compression from epidural metastases. N Engl J Med 327:614-619, 1992

9. Charkes ND, Sklaroff DM, Young I: A critical analysis of strontium bone scanning for detection of metastatic cancer. Am J Roentgenol Radium Ther Bucl Med 96:647-656, 1966

10. Chataigner H, Onimus M: Surgery in spinal metastasis without spinal cord compression: indications and strategy related to the risk of recurrence. Eur Spine J 9:523-527, 2000

11. Chen LH, Chen WJ, Niu CC, et al: Anterior reconstructive spinal surgery with Zielke instrumentation for metastatic malignancies of the spine. Arch Orthop Trauma Surg 120:27-31, 2000

12. Chow TS, McCutcheon IE: The surgical treatment of metastatic spinal tumors within the intradural extramedullary compartment. J Neurosurg 85:225-230, 1996

13. Cloward RB: The anterior approach for removal of ruptured cervical disks. J Neurosurg 15:602-617, 1958

14. Colletti PM, Siegel HJ, Woo MY, et al: The impact on treatment planning of MRI of the spine in patients suspected of vertebral metastasis: an efficacy study. Comput Med Imaging Graph 20:159-162, 1996

15. Connolly ES Jr, Winfree CJ, McCormick PC, et al: Intramedullary spinal cord metastasis: report of three cases and review of the literature. Surg Neurol 46:329-338, 1996

16. Constans JP, de Divitiis E, Donzelli R, et al: Spinal metastases with neurological manifestations. Review of 600 cases. J Neurosurg 59:111-118, 1983

17. Cooper PR, Errico TJ, Martin R, et al: A systematic approach to spinal reconstruction after anterior decompression for neoplastic disease of the thoracic and lumbar spine. Neurosurgery 32: $1-8,1993$

18. Costigan DA, Winkelman MD: Intramedullary spinal cord metastasis. A clinicopathological study of 13 cases. J Neurosurg 62:227-233, 1985

19. Cross GO, White HL, White LP: Acrylic prosthesis of the fifth cervical vertebra in multiple myeloma. Technical note. J Neurosurg 35:112-114, 1971

20. Day GA, McPhee IB, Swanson C, et al: Outcomes following treatment of metastatic spine tumors. Bull Hosp Jt Dis 57: $11-15,1998$ 
21. Delattre JY, Arbit E, Thaler HT, et al: A dose-response study of dexamethasone in a model of spinal cord compression caused by epidural tumor. J Neurosurg 70:920-925, 1989

22. Edelson RN, Deck MD, Posner JB: Intramedullary spinal cord metastases. Clinical and radiographic findings in nine cases. Neurology 22:1222-1231, 1972

23. Fielding JW, Pyle RN Jr, Fietti VG Jr: Anterior cervical vertebral body resection and bone-grafting for benign and malignant tumors. A survey under the auspices of the Cervical Spine Research Society. J Bone Joint Surg (Am) 61:251-253, 1979

24. Fornasier VL, Horne JG: Metastases to the vertebral column. Cancer 36:590-594, 1975

25. Fourney DR, Abi-Said D, Rhines LD, et al: Simultaneous anterior-posterior approach to the thoracic and lumbar spine for the radical resection of tumors followed by reconstruction and stabilization. J Neurosurg 94 (Spine 2):232-244, 2001

26. Ghogawala Z, Mansfield FL, Borges LF: Spinal radiation before surgical decompression adversely affects outcomes of surgery for symptomatic metastatic spinal cord compression. Spine 26:818-824, 2001

27. Gilbert RW, Kim JH, Posner JB: Epidural spinal cord compression from metastatic tumor: diagnosis and treatment. Ann Neurol 3:40-51, 1978

28. Gokaslan ZL: Spine surgery for cancer. Curr Opin Oncol 8: 178-181, 1996

29. Gokaslan ZL, York JE, Walsh GL, et al: Transthoracic vertebrectomy for metastatic spinal tumors. J Neurosurg 89: 599-609, 1998

30. Grant R, Papadopoulos SM, Greenberg HS: Metastatic epidural spinal cord compression. Neurol Clin 9:825-841, 1991

31. Greenberg HS, Kim JH, Posner JB: Epidural spinal cord compression from metastatic tumor: results with a new treatment protocol. Ann Neurol 8:361-366, 1980

32. Haddad P, Thaell JF, Kiely JM, et al: Lymphoma of the spinal extradural space. Cancer 38:1862-1866, 1976

33. Hall AJ, Mackay NN: The results of laminectomy for compression of the cord and cauda equina by extradural malignant tumour. J Bone Joint Surg Br 55:497-505, 1973

34. Hammerberg KW: Surgical treatment of metastatic spine disease. Spine 17:1148-1153, 1992

35. Harada M, Shimizu A, Nakamura Y, et al: Role of the vertebral venous system in metastatic spread of cancer cells to the bone. Adv Exp Med Biol 324:83-92, 1992

36. Harrington KD: Anterior cord decompression and spinal stabilization for patients with metastatic lesions of the spine. J Neurosurg 61:107-117, 1984

37. Harrington PR, Dickson JH: Spinal instrumentation in the treatment of severe progressive spondylolisthesis. Clin Orthop 117:157-163, 1976

38. Hatrick NC, Lucas JD, Timothy AR, et al: The surgical treatment of metastatic disease of the spine. Radiother Oncol 56: 335-339, 2000

39. Heldmann U, Myschetzky PS, Thomsen HS: Frequency of unexpected multifocal metastasis in patients with acute spinal cord compression. Evaluation by low-field MR imaging in cancer patients. Acta Radiol 38:372-375, 1997

40. Helweg-Larsen S: Clinical outcomes in metastatic spinal cord compression. A prospective study of 153 patients. Acta Neurol Scand 94:269-275, 1996

41. Helweg-Larsen S, Sorensen PS, Kreiner S: Prognostic factors in metastatic spinal cord compression: a prospective study using multivariate analysis of variables influencing survival and gait function in 153 patients. Int J Radiat Oncol Biol Phys 46: 1163-1169, 2000

42. Helweg-Larsen S, Wagner A, Kjaer L, et al: Comparison of myelography combined with postmyelographic spinal CT and MRI in suspected metastatic disease of the spinal canal. J Neurooncol 13:231-237, 1992

43. Hess T, Kramann B, Schmidt E, et al: Use of preoperative vas- cular embolization in spinal metastasis resection. Arch Orthop Trauma Surg 116:279-282, 1997

44. Hollis PH, Malis LI, Zappulla RA: Neurological deterioration after lumbar puncture below complete spinal subarachnoid block. J Neurosurg 64:253-256, 1986

45. Holness RO, Huestis WS, Howes WJ, et al: Posterior stabilization with an interlaminar clamp in cervical injuries: technical note and review of the long term experience with the method. Neurosurgery 14:318-322, 1984

46. Ippolito V, Micheletti E, Saccalani M, et al: Radiotherapy and spinal brace: still first-choice treatment for vertebral metastases from breast cancer. Chir Organi Mov 83:177-183, 1998

47. Katagiri H, Takahashi M, Inagaki J, et al: Clinical results of nonsurgical treatment for spinal metastases. Int J Radiat Oncol Biol Phys 42:1127-1132, 1998

48. Keogh C, Bergin D, Brennan D, et al: MR imaging of bone tumors of the cervical spine. Magn Reson Imaging Clin N Am 8:513-527, 2000

49. Khaw FM, Worthy SA, Gibson MJ, et al: The appearance on MRI of vertebrae in acute compression of the spinal cord due to metastases. J Bone Joint Surg Br 81:830-834, 1999

50. Kim HJ, Ryu KN, Choi WS, et al: Spinal involvement of hematopoietic malignancies and metastasis: differentiation using MR imaging. Clin Imaging 23:125-133, 1999

51. Kim RY, Smith JW, Spencer SA, et al: Malignant epidural spinal cord compression associated with a paravertebral mass: its radiotherapeutic outcome on radiosensitivity. Int J Radiat Oncol Biol Phys 27:1079-1083, 1993

52. Klekamp J, Samii H: Surgical results for spinal metastases. Acta Neurochir (Wien) 140:957-967, 1998

53. Kovner F, Spigel S, Rider I, et al: Radiation therapy of metastatic spinal cord compression. Multidisciplinary team diagnosis and treatment. J Neurooncol 42:85-92, 1999

54. Leviov M, Dale J, Stein M, et al: The management of metastatic spinal cord compression: a radiotherapeutic success ceiling. Int J Radiat Oncol Biol Phys 27:231-234, 1993

55. Livingston KE, Perrin RG: The neurosurgical management of spinal metastases causing cord and cauda equina compression. J Neurosurg 49:839-843, 1978

56. Luque ER: Interpeduncular segment fixation. Clin Orthop 203:54-57, 1986

57. Macdonald DR: Clinical manifestations, in Sundaresan N, Schmidek HH, Schiller AL, et al (eds): Tumors of the Spine. Diagnosis and Clinical Management. Philadelphia: WB Saunders, 1990, p 6-21

58. Manke C, Bretschneider T, Lenhart M, et al: Spinal metastases from renal cell carcinoma: effect of preoperative particle embolization on intraoperative blood loss. AJNR Am J Neuroradiol 22:997-1003, 2001

59. Maranzano E, Latini P, Beneventi S, et al: Radiotherapy without steroids in selected metastatic spinal cord compression patients. A phase II trial. Am J Clin Oncol 19:179-183, 1996

60. Maranzano E, Latini P, Checcaglini F, et al: Radiation therapy in metastatic spinal cord compression. A prospective analysis of 105 consecutive patients. Cancer 67:1311-1317, 1991

61. Maranzano E, Latini P, Perrucci E, et al: Short-course radiotherapy (8 Gy X 2) in metastatic spinal cord compression: an effective and feasible treatment. Int J Radiat Oncol Biol Phys 38:1037-1044, 1997

62. Matsui H, Tatezaki S, Tsuji H: Ceramic vertebral body replacement for metastatic spine tumors. J Spinal Disord 7:248-254, 1994

63. McPhee IB, Williams RP, Swanson CE: Factors influencing wound healing after surgery for metastatic disease of the spine. Spine 23:726-733, 1998

64. Mirovsky Y, Tamir L, Pollak L, et al: Hartshill spinal fixation in vertebral metastasis. Am J Orthop 28:347-350, 1999

65. Nottebaert M, von Hochstetter AR, Exner GU, et al: Metastatic 
carcinoma of the spine. A study of 92 cases. Int Orthop 11: 345-348, 1987

66. Öge HK, Aydin S, Cagavi F, et al: Migration of pacemaker lead into the spinal venous plexus: case report with special reference to Batson's theory of spinal metastasis. Acta Neurochir 143:413-416, 2001

67. Onimus M, Papin P, Gangloff S: Results of surgical treatment of spinal thoracic and lumbar metastases. Eur Spine J 5: 407-411, 1996

68. Ono K, Tada K: Metal prosthesis of the cervical vertebra. J Neurosurg 42:562-566, 1975

69. Perrin RG: Metastatic tumors of the axial spine. Curr Opin Oncol 4:525-532, 1992

70. Perrin RG, Livingston KE: Neurosurgical treatment of pathological fracture-dislocation of the spine. J Neurosurg 52: 330-334, 1980

71. Perrin RG, Livingston KE, Aarabi B: Intradural extramedullary spinal metastasis. A report of 10 cases. J Neurosurg 56:835-837, 1982

72. Perrin RG, McBroom RJ: Anterior versus posterior decompression for symptomatic spinal metastasis. Can J Neurol Sci 14:75-80, 1987

73. Perrin RG, McBroom RJ: Spinal fixation after anterior decompression for symptomatic spinal metastasis. Neurosurgery 22:324-327, 1988

74. Portenoy RK, Galer BS, Salamon O, et al: Identification of epidural neoplasm. Radiography and bone scintigraphy in the symptomatic and asymptomatic spine. Cancer 64:2207-2213, 1989

75. Robinson RA, Southwick WO: Surgical approaches to the cervical spine. Am Acad Orthop Surg 17:299-330, 1960

76. Robinson RA, Smith GW: Anterolateral cervical disc removal and interbody fusion for cervical disc syndrome. Bull John Hopkins Hosp 96:223-224, 1955 (Abstract)

77. Rodichok LD, Harper GR, Ruckdeschel JC, et al: Early diagnosis of spinal epidural metastases. Am J Med 70:1181-1188, 1981

78. Rogers WA: Treatment of fracture-dislocation of the cervical spine. J Bone Joint Surg 24:245-258, 1942

79. Rompe JD, Hopf CG, Eysel P: Outcome after palliative posterior surgery for metastatic disease of the spine-evaluation of 106 consecutive patients after decompression and stabilisation with the Cotrel-Dubousset instrumentation. Arch Orthop Trauma Surg 119:394-400, 1999

80. Roscoe MW, McBroom RJ, St Louis E, et al: Preoperative embolization in the treatment of osseous metastases from renal cell carcinoma. Clin Orthop 238:302-307, 1989

81. Roy-Camille R, Saillant G, Berteaux D, et al: Osteosynthesis of thoraco-lumbar spine fractures with metal plates screwed through the vertebral pedicles. Reconstr Surg Traumatol 15: 2-16, 1976

82. Salvati M, Cervoni L, Puzzilli F, et al: Metastatic spinal cord compression. Clinical remarks. Minerva Chir 53:727-730, 1998

83. Schick U, Marquardt G, Lorenz R: Intradural and extradural metastases. Neurosurg Rev 24:1-7, 2001

84. Schiff D, O'Neill BP: Intramedullary spinal cord metastases: clinical features and treatment outcome. Neurology 47: 906-912, 1996

85. Schiff D, O'Neill BP, Suman VJ: Spinal epidural metastasis as the initial manifestation of malignancy: clinical features and diagnostic approach. Neurology 49:452-456, 1997

86. Schulte M, Schultheiss M, Hartwig E, et al: Vertebral body replacement with a bioglass-polyurethane composite in spine metatstases--clinical, radiological and biomechanical results. Eur Spine J 9:437-444, 2000

87. Seichi A, Kondoh T, Hozumi T, et al: Intraoperative radiation therapy for metastatic spinal tumors. Spine 24:470-475, 1999

88. Sioutos PJ, Arbit E, Meshulam CF, et al: Spinal metastases from solid tumors. Analysis of factors affecting survival. Cancer 76:1453-1459, 1995

89. Solberg A, Bremnes RM: Metastatic spinal cord compression: diagnostic delay, treatment, and outcome. Anticancer Res 19: 677-684, 1999

90. Sorensen S, Borgesen SE, Rhode K, et al: Metastatic epidural spinal cord compression. Results of treatment and survival. Cancer 65:1502-1508, 1990

91. Stark RJ, Henson RA, Evans SJ: Spinal metastases. A retrospective survey from a general hospital. Brain 105:189-213, 1982

92. Steffee AD, Biscup RS, Sitkowski DJ: Segmental spine plates with pedicle screw fixation. A new internal fixation device for disorders of the lumbar and thoracolumbar spine. Clin Orthop 203:45-53, 1986

93. Sundaresan N, Digiancinto GV, Hughes JE, et al: Treatment of neoplastic spinal cord compression: results of a prospective study. Neurosurgery 29:645-650, 1991

94. Sundaresan N, Galicich JH, Bains MS, et al: Vertebral body resection in the treatment of cancer involving the spine. Cancer 53:1393-1396, 1984

95. Sundaresan N, Steinberger AA, Moore F, et al: Indications and results of combined anterior-posterior approaches for spine tumor surgery. J Neurosurg 85:438-446, 1996

96. Tindal S, Perrin RG: Anesthesia for surgical management of spinal metastases. Probl Anesth 5:80-90, 1991

97. Ushio Y, Posner R, Kim JH, et al: Experimental spinal cord compression by epidural neoplasm. Neurology 27:422-429, 1977

98. Ushio Y, Posner R, Kim JH, et al: Treatment of experimental spinal cord compression caused by epidural neoplasms. J Neurosurg 47:380-390, 1977

99. Vecht CJ, Haaxma-Reiche H, van Putten WL, et al: Initial bolus of conventional versus high-dose dexamethasone in metastatic spinal cord compression. Neurology 39:1255-1257, 1989

100. Weigel B, Maghsudi M, Neumann C, et al: Surgical management of symptomatic spinal metastases. Postoperative outcome and quality of life. Spine 24:2240-2246, 1999

101. Willis RA: The Spread of Tumours in the Human Body, ed 2. London: Butterworth, 1952

102. Wise JJ, Fischgrund JS, Herkowitz HN, et al: Complication, survival rates, and risk factors of surgery for metastatic disease of the spine. Spine 24:1943-1951, 1999

103. Wong DA, Fornasier VL, MacNab I: Spinal metastases: the obvious, the occult, and the impostors. Spine 15:1-4, 1990

104. Wong CS, Van Dyk J, Milosevic M, et al: Radiation myelopathy following single courses of radiotherapy and retreatment. Int J Radiat Oncol Biol Phys 30:575-581, 1994

105. Young RF, Post EM, King GA: Treatment of spinal epidural metastases. Randomized prospective comparison of laminectomy and radiotherapy. J Neurosurg 53:741-748, 1980

Manuscript received October 15, 2001.

Accepted in final form November 13, 2001.

Address reprint requests to: Richard G. Perrin, M.D., Division of Neurosurgery, University of Toronto, St. Michael's Hospital, 55 Queen Street East, 9th Floor, Suite 948, Toronto, Ontario M5B 1R6, Canada. email: richard.perrin@utoronto.ca. 